\title{
Accountants Need To Be Prepared For The Big Question: Should I Move To The Cloud?
}

Sheree M. Corkern, Mississippi College University, USA

Sara B. Kimmel, Mississippi College University, USA

Billy Morehead, Mississippi College University, USA

\begin{abstract}
Cloud computing is transforming the accounting profession and gaining worldwide attention. According to Jeff Drew, senior editor covering technology for the Journal of Accountancy, cloud computing was one of the most talked about topics during a recent AICPA Practitioners Symposium and TECH+ Conference. Gartner Inc., a world leader in information technology and analysis, projects worldwide cloud service revenues to reach \$148.8 billion in 2014. Notwithstanding its rave reviews, many continue to resist the cloud. Whether from ignorance of its workings and advantages or uncertainty due to its newness and challenges, questions and concerns weigh heavily among those contemplating its adoption. Accountants who stay abreast of new developments within the field of cloud computing, becoming not only educated but experienced, will be able to provide assistance and advice in an organization's assessment process of this new cloud-based delivery platform. This article defines cloud computing and highlights some of the associated advantages and challenges faced by organizations considering cloud services.
\end{abstract}

Keywords: Accountants; Cloud Computing; Cloud Services

\section{INTRODUCTION}

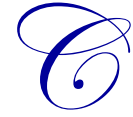

loud computing is becoming a powerful and valuable tool for companies and has been identified as one of the key technology trends that accountants should stay abreast of over the next decade. Grabbing the attention of the entire business community as a new business platform, its many advantages include instant accessibility, cost savings, improved productivity, and increased mobility. Not every organization understands cloud computing's relevance to their business, and they are searching for answers to many questions. They rely heavily on their CPAs and management accountants to assist them in understanding new technologies. They are seeking answers to questions, such as:

- What are the advantages of using a cloud computing platform versus the traditional in-house computing center?

- $\quad$ Should our organization make the switch?

- Will the switch increase our bottom line?

- Will our data be safe?

- What will be the challenges of this move?

- In short, is cloud computing appropriate for our business, and will it add value to our organization?

Organizations are increasingly moving to the cloud because of the many advantages cloud computing offers in terms of availability and scalability. However, while benefits of cloud computing are well received, many organizations are still cautious about its overall security and reliability. They must address several important key issues before considering the switch from the traditional in-house model to cloud computing. 
A basic understanding of how cloud computing works and what it can do for an organization can provide accountants a competitive edge and a new challenge. Accountants are in a position to raise awareness of this new paradigm, including its advantages and its challenges. Organizations may then be able to effectively evaluate this new computing platform and ultimately decide if it is a good match for them.

This paper presents a definition of cloud computing found in the Committee of Sponsoring Organizations (COSO) of the Treadway Commission's "Enterprise Risk Management for Cloud Computing" report and then explores cloud computing in terms of presenting and addressing some of the advantages and challenges of migrating a business' data processing and storage to the cloud.

\section{Definition}

There has been much confusion as to what cloud computing really means. Some have even implied that it is a new marketing term used to describe an existing service. According to Wikipedia, the cloud computing concept dates back to the 1950s when mainframe computers were used and a practice evolved that allowed multiple users to share the CPU time to eliminate periods of inactivity, thus allowing a greater return on the investment. Today, users think of cloud computing as letting outside experts take care of the management, maintenance, support, updates, and upgrades of an organization's data center.

In June 2012, the Committee of Sponsoring Organizations (COSO) of the Treadway Commission - a joint initiative of five private sector organizations (American Institute of CPAs, Institute of Management Accountants, Financial Executives International, American Accounting Association, and Institute of Internal Auditors) - released a report providing organization guidance on cloud computing. This report defined it as "a computing resource deployment and procurement model that enables an organization to obtain its computing resources and applications from any location via an Internet connection. Depending on the cloud solution model an organization adopts, all or parts of the organization's hardware, software and data might no longer reside on its own technology infrastructure. Instead, all of these resources may reside in a technology center shared with other organizations and managed by a third-party vendor." For the purpose of this paper, the COSO definition will be used.

Within this cited definition, notice the terms computing, model, any location, Internet, hardware, software, data, shared, and third-party. Simply said, cloud computing is using a new business platform that allows for a company's computing resources to be deployed via the Web, therefore eliminating the on-site technology infrastructure such as servers, software, and IT staff who would no longer be needed. Unlike traditional models where software applications are installed on the company's computers or servers, with cloud computing, software applications are accessed through an Internet connection and are rented rather than purchased. In other words, organizations will not be buying software; instead, they will be buying access to applications, data, infrastructure resources, etc.

Software applications delivered through cloud computing are designed to be multitenant, allowing many users access to the same software at the same time. Thus, multiple organizations share processing power and space that is managed by a third-party cloud service provider. Also, users within the organizations have the ability to work from virtually anywhere and at any time. This allows even the smallest organization the ability to connect, access, and interact worldwide on a nearly instantaneous basis. According to Jim Bourke, chair of the AICPA TECH+ conference, from 2012 through 2014 cloud computing will simply be the way organizations do business. Companies, customers, and vendors will all be connected via the cloud.

\section{Primary Reasons Users Migrate To The Cloud: Advantages And Opportunities}

To understand what cloud computing can do for your business, it is important to understand what basic advantages exist over the traditional in-house data center. Today, organizations are migrating to the cloud because of the many competitive advantages offered by this technology. Although the potential advantages that could be derived from cloud computing versus the traditional platform are numerous, this paper will discuss advantages that can be derived from its accessibility, flexibility, and scalability features. 


\section{Accessibility/Flexibility}

Cloud computing enables organizations to access their data via the Internet from any place in the world and at any time. Businesses demand access to data 24 hours a day, seven days a week, and boundaries are becoming less defined with virtual companies emerging all the time. This capability of anywhere, anytime access allows for an organization's work to become more flexible, distributive, and collaborative.

Collaboration among all of the stakeholders of an organization enables them to communicate in increasingly effective ways that were not previously possible. For example, this feature gives organizations with multiple locations the opportunity to collaborate and distribute their work among the many company locations. When one location is overloaded with work and another is slack, sharing the overload is not a problem. Not only does the accessibility feature allow for the sharing of work among the various locations, it also enables many employees of the organization to have a more flexible work schedule. Using Web-enabled devices, such as smartphones and laptops with an Internet connection, facilitates anytime access from anywhere in the world to their company files. Employees desiring to achieve a balance between work and other aspects of their lives can use cloud computing as a means of adapting their working environments accordingly.

\section{Scalability}

All businesses are subject to change. Some grow while others downsize. The scalability of cloud computing is one of the primary reasons that businesses migrate to the cloud. Scalability enables an organization to obtain large amounts of computing resources for peak performance periods without investing in excess computing capacity. Scalability stems from the idea that any quantity of computing resources can be purchased at any time, and companies pay for the services they use based on consumption. This feature of cloud computing is one of the most important because it allows a large-scale cloud service provider (CSP) the ability to provide computing resources to multiple users, each requiring varying levels of service. According to Laurie MaCabe and Sanjeev Aggarval (2012), in a traditional on-premise IT environment, the average server-utilization rate is estimated at 5 to 15 percent of total capacity. The traditional server was designed to accommodate peak-use periods, meaning that the majority of its capacity is idle most of the time. With scalability, companies use the required amount of computing resources needed at all times and they only pay for the resources consumed. This capability is convenient for businesses because most businesses work around a seasonal cycle and have different workload requirements throughout their year. Thus, varying amounts of computing resources are required. With scalability, the company can instantly purchase the exact amount of computing resources needed. Simply put, scalability gives the organization the ability to scale its computing resources up or down as business conditions dictate. As users are able to access applicable computer and IT services they need from the cloud, capital investments in IT infrastructure and application software may be substantially reduced.

\section{Primary Concerns Inherent To Cloud Computing: Security And Reliability}

As technological solutions become increasingly available and flexible, keeping pace with the ever-changing mobile workforce and the even more mobile client pool, organizations are faced with challenges inherent to the process. Cloud computing is no exception. Two of the top challenges inherent to cloud computing are security and reliability, which are generally of concern for most businesses, regardless of the business platform being considered. In order for businesses to experience the full benefits of cloud computing, the issues of security and reliability must be addressed and resolved. Only when companies are reassured of the safety and reliability of the products and services offered with cloud computing will they feel comfortable migrating their data and applications from their own computers onto the cloud.

Organizations can be reluctant to migrate to the cloud because they perceive such a move as diminishing the organization's control over its own data. In essence, the organization is relinquishing a measure of responsibility for service reliability, as well as control of information security to a third party. Each organization must find ways to address such uncertainties before choosing to adopt cloud computing. 


\section{Security}

Cloud security has always been discussed as one of the biggest challenges that organizations must overcome before they will adopt cloud computing. Threats to the security of cloud computing become more numerous all the time. Placing your data in the cloud has expanded the number of potential targets for cyber-attacks, and businesses must take the necessary precautions and apply the best approaches available to protect their data. Even though users may feel there is a higher likelihood for a security breach, findings are indicating just the opposite. According to Michael Smith, a member of the AICPA's IT Executive Committee, data can be even more secure on the cloud than it is on the premises because of the additional security measures some cloud service providers have taken. Some of the cloud service providers have Tier 1 data centers that are staffed 24 hours a day. Top-tier cloud service providers often can provide much better data security than small businesses could provide on their own. Many businesses today cannot afford this level of security and they need to understand that the only way to have 100 percent computer security is to have zero computers. Also, if the computer has Internet access, some form of cloud access is already in use. It is highly recommended that businesses always prioritize security first and convenience second. Organizations and cloud service providers must have security controls in place to mitigate the risks they face. There are numerous approaches that can be taken to reduce security risks to an acceptable level. For example, choose a cloud service provider that has had a specialized audit of their data center and has received an AICPA Service Organization Controls Report (SOC). Another approach would be to use a third-party monitor to test the security of the cloud service provider's website.

Another concern involves data security when proprietary corporate information and confidential customer data are being transmitted, processed, and stored in the cloud. Organizations must face the challenge of keeping their data private and confidential. Many times this data is highly sensitive and a privacy breach would be detrimental. Potential customers struggle with indecisiveness, weighing the advantages of accessibility and scalability versus the challenges of security and reliability. The new platform must be scrutinized, tested, and proven reliable in order for companies to welcome it without reservation.

\section{Reliability}

Another concern related to cloud use is reliability. As cloud-computing services become more secure, organizations begin to address the reliability issue. They are not only concerned about the security of their data, but also about the reliability of the cloud service provider (CSP). A business must be able to have access to its data at all times to support their daily operations and interact with their business community. Any delays in the availability of cloud service could jeopardize the entire business process. Users rely on the CSP to maintain a high uptime percentage to meet their demand. Acceptable levels of uptime are usually expressed as the "five nines"; that is, service is available 99.999 percent of the time. Also, organizations should note that even though the CSP may be up and their data may be available on the Web, availability can still be a problem due to their own inadequate Internet access or small bandwidth. In other words, potential problems rest on their end and not exclusively with the CSP. Organizations need to make sure that they have reliable access to their data even if they have to pay a secondary provider for Internet access in order to overcome the availability challenge. Availability is a crucial feature of cloud computing that organizations expect to have once they adopt this new technology.

The cloud's reliability has been called into question in the past, as in 2011 when portions of Amazon's web services infrastructure went down for several days. Companies must build redundancy into their architectures to withstand a service interruption should one occur. Cloud computing companies are continuously improving the reliability of their services. Overall, cloud reliability records are very good and even better than most in-house operations. For example, Google's Gmail service was available $99.983 \%$ in 2012 or for all but an estimated seven minutes of each month. Overal, cloud reliability records are admirable and the Radicati Group, a technology market research firm, estimates that this is approximately 32 times more reliable than the average corporate e-mail system. According to John Kleeman, founder of the Questionmark assessment software system, cloud computing can be more reliable and provide a higher level of 24/7 uptime than an on-premise infrastructure, providing the company has good Internet connectivity. It is likely to have redundancy built into every component, whereas it may not be cost-effective to have this level of redundancy in an on-premise system. 
Regardless, companies must face the issues of system reliability and security whether the IT functions are in-house or in the cloud. In many respects companies will be dealing with the same issues but from a new perspective. Many CSPs argue that systems and data are more reliable and safer in the cloud because they are managed with more specialized expertise. Human technology has never been perfect, and it never will be. There will always be concerns and challenges inherent in managing it. Cloud computing offers many benefits once issues of security and reliability are recognized and effectively addressed.

\section{CONCLUSION}

No doubt, cloud computing is a major paradigm shift for enterprise organizations, starting with the way services are delivered and the underlying solutions deployed to enable those services through to the end product or service. Even so, misconceptions prevent many organizations from using cloud service to its full potential.

Cloud computing is a topic accountants must familiarize themselves with because many organizations they typically work in or for will seek guidance and direction on this new business platform. Accountants must be in a position to educate their business community about cloud computing and assist them in the assessment process regarding its adoption.

In an interview conducted by the Journal of Accountancy, Gregory LaFollette, CPA/CITP, predicted that in 10 years, premise-based software will almost be nonexistent. According to another one of the interviewees, David Cleslak, former chair of the AICPA IT Executive Committee and a noted technology speaker, the PC and Lotus 1-23 changed the accounting profession in the 1980s and, in the 1990s, it was the Internet. Today, cloud computing is poised to be the next transformational technology. Cleslak also suggested that cloud computing will become critical in the future and it will ultimately support all of the applications and data that run organizations.

Companies will look to their accountants to help them with understanding the advantages and challenges of cloud computing. Accountants must master this new tool to be equipped to provide greater service and add economic value to the organizations that they work with. They need to be prepared to assist organizations in understanding and exploring this new technology and help evaluate whether or not the cloud platform would be a good match. Although the cloud format presents clear incremental advantages over traditional formats, organizations must perceive its value before it can become part of their technology platform.

It is very likely that cloud computing will be the platform of tomorrow that organizations will use to conduct their business. Accountants acquainted with the various aspects of cloud computing will be better equipped to help make the decision whether to move to cloud services or not.

\section{AUTHOR INFORMATION}

Sheree M. Corkern is an Assistant Professor of Accounting at Mississippi College University. Her research interests involve pedagogical issues and the practical issues that surround the accounting industry. She teaches courses in intermediate accounting, principles of accounting, and accounting information systems. E-mail: corkern@mc.edu.

Sara B. Kimmel is an Assistant Professor of Business at Mississippi College University. Her research interests include women in political office, representation of marginalized groups, and motivations and barriers of adult learners. She teaches courses in Global Dimensions of Business and Managing in the Global Environment. E-mail: kimmel@mc.edu.

Billy Morehead is an Associate Professor Business at Mississippi College University. His research interests include research relating to not-for-profit organizations and governmental entities. He teaches course in Governmental Accounting, Financial Accounting and Management Accounting. E-mail: morehead@mc.edu. 


\section{REFERENCES}

1. Aljabre, A. (2012). Cloud computing for increased business value. International Journal of Business and Social Science, 3(1) 234-239.

2. Armbrust, M., Fox, A., Griffith, R., Joseph, A. D., Katz, R., Konwinski, A., Lee, G., Patterson, D., Rabkin, A., Stoica, I., \& Zaharia, M. (2010). A view of cloud computing. Communications of the ACM, 53(4) 5058.

3. Budriene, D., \& Zalieckaite, L. (2012). Cloud computing application in small and medium-sized enterprises. Issues of Business and Law, 25(1), 119-130. Retrieved from http://dx.doi.org/10.520/ibl.2012.11.

4. Callewaert, P., Robinson, P. A., \& Blatman, P. (2009). Deloitte: cloud computing forecasting change: Market overview and perspective consulting. Retrieved from https:/www.deloitte.com/assets/DcomNetherlands/Local\%20Assets/Documents/EN/Services/Consulting/nl_en_consulting_cloud_computing_sec urity_privacy_and_trust.pdf.

5. Chan, W., Leung, E., \& Pili, H. (2012). Enterprise risk management for cloudy computing. Crowe Horwath LLP paper commissioned by COSO (Committee of Sponsoring Organizations of the Treadway

Commission). Retrieved from http://www.coso.org/documents/Cloud\%20Computing\%20Thought\%20Paper.pdf.

6. Chen, L., Liu, Y., Gallagher, M., Pailthorpe, B., Sadiq, S., Shen, H. T., \& Li, X. (2012). Introducing cloud computing topics in curricula. Journal of Information Systems Education, 23(3) 315-324.

7. Christauskas, C., \& Miseviciene, R. (2012). Cloud-computing based accounting for small to medium sized business. Inzinerine Ekonomika - Engineering Economics, 23(1) 14-21.

8. DeFelice, A. (2010, October). Cloud computing - what accountants need to know. Journal of Accountancy, 50-55. Retrieved from http://www.journalofaccountancy.com.

9. Drew, J. (2011, November). Technology 2012 preview: Part 1 - experts explain what should be at the top of your tech wish list for the new year. Journal of Accountancy, 46-52. Retrieved from http://www.journalofaccountancy.com.

10. Drew, J. (2012, February). Heads in the clouds: Part 1 - CPAs discuss advantages, challenges of new computing paradigm. Journal of Accountancy, 20-23. Retrieved from http://www.journalofaccountancy.com.

11. Drew, J. (2012, June). Technology and cpas: Visions of the future. Journal of Accountancy, $110-118$. Retrieved from http://www.journalofaccountancy.com.

12. Drew, J. (2012, August). Managing cybersecurity risks - mobile and cloud open doors to opportunities and threats. Journal of Accountancy, 44-48. Retrieved from http://www.journalofaccountancy.com.

13. Durkee, D. (2010). Why cloud computing will never be free. Communications of the ACM, 53(5) 62-69.

14. Garrison, G., Kim, S., \& Wakefield, R. L. (2012). Success factors for deploying cloud computing. Communications of the ACM, 55(9) 62-68.

15. Gartner Says Worldwide Cloud Services Market to Surpass \$68 Billion in 2010, Gartner, Inc. (June 22, 2010). Retrieved from http://www.gartner.com/newsroom/id/1389313.

16. Gold, J. (2012). Protection in the cloud: Risk management and insurance for cloud computing. Journal of Internet Law, 5(12) 23-28.

17. Hayes, B. (2008). Cloud computing - as software migrates from local pcs to distant internet servers, users and developers alike go along for the ride. Communications of the ACM, 51(7) 9-11.

18. Helland, P. (2013). Condos and clouds. Communications of the ACM, 56(1) 50-59.

19. Juels, A., \& Oprea, A. (2013). New approaches to security and availability for cloud data. Communications of the ACM. 56(2) 64-73.

20. Kalyvas, J. R., Overly, M. R., \& Karlyn, M. A. (2013). Cloud computing: A practical framework for managing cloud computing risk - part I. Intellectual Property \& Technology Law Journal, 25(3) 7-18.

21. Kalyvas, J. R., Overly, M. R., \& Karlyn, M. A. (2013). Cloud computing: A practical framework for managing cloud computing risk - part II. Intellectual Property \& Technology Law Journal, 25(4) 19-27.

22. Kleeman, J. (2013). On-demand or on-premise: Which is better for talent management? Retrieved from http://blog.questionmark.com/on-demand-or-on-premise-which-is-better-for-talent-management. 
23. McAfee, A. (2012). What Every CEO Needs to Know About the Cloud. Retrieved from http://ebusiness.mit.edu/research/Briefs/McAfee_What_Every_CEO_Needs_to_Know_About_the_Cloud.p df.

24. McCabe, L., \& Aggarwal, S. (2012). Clearing the Clouds for Midmarket Businesses. Retrieved from http://www.emc.com/collateral/analyst-reports/smb-group-clearing-clouds-ar.pdf.

25. Mangiuc, D-M. (2012). Security issues of cloud based services - a guide for managers. Review of International Comparative Management, 13(3) 468-477.

26. Maughan, A. (2013). Europe offers incentives to cloud computing growth. Intellectual Property \& Technology Law Journal, 25(2) 14-19.

27. McKendrick, J. (2012). 7 predictions for cloudy computing in 2013 that make perfect sense. Forbes, Retrieved from http://www.forbes.com/sites/joemckendrick/2012/12/09/7-predictions-for-cloudcomputing-in-2013-that-make-perfect-sense.

28. Mell, P., \& Grance, T. (2011). The NIST definition of cloud computing. National Institute of Standards and Technology, U.S. Department of Commerce. NIST Special Publication 800-145. Retrieved from http://csrc.nist.gov/publications/nistpubs/800-145/SP800-145.pdf.

29. Schwartz, P. M. (2013). Information privacy in the cloud. University of Pennsylvania Law Review, 161(1) 1623-1662.

30. Security breaches in the public cloud (2012, September). Journal of Accountancy, 12. Retrieved from http://www.journalofaccountancy.com.

31. Sunyaev, A., \& Schneider, S. (2013). Cloud services certification: How to address the lack of transparency, trust, and acceptance in cloud services. Communications of the ACM, 56(2) 33-36.

32. The computer revolution. (1965, April). The Journal of Accountancy, 31-32.

33. Vakil, F., Lu, V., \& Russakoff, A. (2012). Recent developments in cloud computing and high speed connections for business practices. Review of Business, 3(1) 111-118.

34. Von Solms, R., \& Viljoen, M. (2012). Cloud computing service value: A message to the board, South African Journal of Business Management, 43(4) 73-81.

35. Zhand, L., \& GU, W. (2013). The simple analysis of impact on financial outsourcing because of the rising of cloud accounting. Asian Journal of Business Management, 5(1) 140-143. 


\section{NOTES}

